\title{
Polskie Forum Rodziców - inicjatywa Fundacji Instytut Wiedzy o Rodzinie i Społeczeństwie
}

Wiosną 2019 roku swoje działanie zainaugurował portal Polskie Forum Rodziców ${ }^{1}$, którego zasadniczym celem jest tworzenie przestrzeni, w której regularnie i na bieżąco prezentowane, analizowane i komentowane będą zjawiska, trendy oraz wyzwania dotyczące rodziny i rodzicielstwa. Portal ten stanowi pierwszą inicjatywę Fundacji Instytut Wiedzy o Rodzinie i Społeczeństwie, którą przed rokiem utworzyli doświadczeni badacze, dziennikarze, redaktorzy oraz praktycy pracujący w obszarze polityki rodzinnej, których połączyło wspólne przekonanie, że rodzina jest tym, co wpływa na harmonijne funkcjonowanie całej struktury społecznej.

$\mathrm{Na}$ portalu regularnie publikowane są artykuły, felietony, wywiady, komentarze i porady poświęcone tematyce rodzicielstwa, w tym takim tematom jak prawa rodziców, wychowanie, edukacja, zdrowie, ekonomia, aktywność w ruchach i gremiach rodzicielskich oraz kultura rodzinna. Ich autorami są doświadczeni redaktorzy oraz eksperci i praktycy z wieloletnim

$1 \quad$ www.polskieforumrodzicow.pl. 
doświadczeniem, których łączy wspólna pasja, jaką jest rodzicielstwo. W ten sposób portal stara się aktywizować, integrować i wyposażać w aktualną i rzetelną wiedzę środowisko rodziców. Przekazywane informacje dotyczą zagadnień bieżących w kontekście systemów oświaty i edukacji, opieki zdrowotnej, mediów, prawa oraz gospodarki. Są ukierunkowane na wyposażanie odbiorców w niezbędne kompetencje sprzyjające rozwojowi oraz międzypokoleniowej transmisji dojrzałych postaw obywatelskich. Ponadto na portalu ukazywane są wyniki badań, a także promowane organizacje i inicjatywy społeczne, które swymi działaniami wzmacniają i rozwijają zaangażowanie rodziców w wymiarze społeczeństwa obywatelskiego. Dotychczas ukazało się tam kilkaset oryginalnych artykułów. Narzędziem używanym jest dla wsparcia promocyjnego portalu jest profil PFR w mediach społecznościowych ${ }^{2}$, który dodatkowo stanowi platformę bieżącej wymiany informacji i poglądów między czytelnikami, co dostarcza informacji o ich opiniach i preferencjach, a dzięki temu pomaga budować społeczność rodziców zaangażowanych, świadomych praw i obowiązków, angażujących się w wychowanie i rozwój dzieci, a także wspierających działania edukacyjne np. szkół. Treści z portalu PFR cytowały jak dotąd takie media jak TVP Info, TVP3 Poznań, TV Republika, Telewizja „Trwam”, PolskieRadio24.pl, Radio Poznań, Radio Maryja, Wprost.pl, DoRzeczy.pl, Niezalezna.pl, Aktualności24.com, Wprawo.pl, Nczas.com, Plportal.pl, PCh24.pl, PolskaNiepodlegla.pl, ePoznan.pl, „Gazeta Polska Codziennie”, „Gazeta Polska”, „Przewodnik Katolicki”, „Głos dla Życia” oraz „Miłujcie się”. Artykuły poświęcone bezpośrednio naszemu portalowi ukazały się w „Gazecie Polskiej Codziennie”, „Głosie dla Życia”, oraz „Miłujcie się”, a w TVP3 wyemitowany został program Lustra poświęcony PFR. Prowadzenie portalu oraz profilu na Facebooku systematycznie poszerza wiedzę rodziców, wspiera rozwój ich kompetencji obywatelskich oraz dostarcza aktualnych informacji istotnych dla tej grupy docelowej. Tym samym portal realizuje misję medium obywatelskiego, pełniąc zarazem funkcję ambasadora spraw rodziców, którzy borykają się z kłopotami w obszarach m.in. komunikacji ze szkołą, interwencji w urzędach (np. kuratoriach, ministerstwach - Ministerstwie Edukacji Narodowej i Ministerstwie Rodziny, Pracy i Polityki Społecznej). Warto tu dodać, że redaktorzy PFR przeprowadzili już wiele rozmów $\mathrm{z}$ rodzicami w ramach interwencji rodzicielskich, wystosowali wiele oficjalnych pism do kuratoriów, wydziałów oświaty i MEN. W ten

2 www.facebook.com/PolskieForumRodzicow. 
sposób PFR staje się przestrzenią i wsparciem dla rodziców w wyrażaniu ich opinii i stanowi ich słyszalny głos w przestrzeni publicznej, który dociera właśnie tam, gdzie nierzadko nie słychać obaw, wątpliwości czy niepewności pojedynczego rodzica.

Fundacja Instytut Wiedzy o Rodzinie i Społeczeństwie, która założyła i prowadzi portal, rozwija także aktywność badawczą i naukową dotyczącą roli, pozycji i kondycji rodziny w Polsce i świecie XXI wieku - dziś bowiem dokonują się zasadnicze i wielowymiarowe zmiany natury społeczno-kulturowej. W tym kontekście zespół Instytutu dostrzega, że rola rodzin w rozwoju gmin, miast i państw wymaga stałej analizy, badania i opisywania, oraz uważa, że od tej wiedzy zależeć będą kondycja i warunki życia przyszłych pokoleń. Eksperci Instytutu Wiedzy o Rodzinie i Społeczeństwie badają więc procesy społeczno-kulturowe, demograficzne i ekonomiczne w celu wyjaśniania i zrozumienia ich współzależności z zachowaniami i dążeniami dorosłych członków rodzin. W ten sposób dostarczają pogłębionych analiz ukazujących wpływ funkcjonowania rodziny na jakość i poziom życia, strukturę społeczną, a także perspektywy rozwoju społeczno-gospodarczego. Dzięki kompetencjom badaczy z różnych dyscyplin oraz praktyków z zakresu polityki rodzinnej współtworzących zespół Instytutu formułowane są rzetelne i kompleksowe komentarze dotyczące celów, preferencji oraz wartości, które brane są pod uwagę przez współczesnego człowieka w podejmowaniu decyzji dotyczących z jednej strony założenia rodziny, a z drugiej odnoszących się do funkcjonowania i rozwoju rodzin już istniejących.

W swych publikacjach redaktorzy PFR wraz z ekspertami Instytutu podejmują właśnie tę tematykę, starając się jednocześnie o upowszechnianie rzetelnej wiedzy i poszerzanie świadomości na temat fundamentalnego znaczenia małżeństwa i rodzicielstwa dla społeczeństwa. W ramach swojej aktywności zespół Instytutu nie tylko uczestniczy w konferencjach, sympozjach naukowych oraz realizuje warsztaty dla samorządowców, ale także współpracuje z mediami, ośrodkami badawczymi oraz organizacjami pozarządowymi. Te szeroko zakrojone działania mają na celu nie tylko analizę i opis aktualnego stanu badanych zjawisk, ale także tworzenie prognoz o charakterze społecznym, demograficznym, gospodarczym i kulturowym dla wybranych regionów Polski. Jednocześnie Instytut jest otwarty na współpracę z przedstawicielami wszystkich szczebli zarządzania procesami 
rozwoju miast, gmin i państwa, a także menedżerami firm odpowiedzialnych za planowanie i realizację wieloletnich strategii rozwoju.

Oprócz stworzenia portalu PFR Fundacja Instytut Wiedzy o Rodzinie i Społeczeństwie w listopadzie 2019 roku, we współpracy z Radiem Poznań, zainicjowała cykl ponad osiemdziesięciu audycji pt. Dylematy Mamy i Taty, w których jej eksperci - naukowcy, pedagodzy, dziennikarze, lekarze, aktywni społecznie rodzice i przedstawiciele organizacji pozarządowych wypowiadają się na tematy bliskie każdemu rodzicowi. Ponadto w marcu 2020 roku we współpracy z Fundacją Edukacji Zdrowotnej i Psychoterapii organizacja opublikowała poradnik informacyjno-profilaktyczny dla rodziców dzieci w wieku od siedmiu do piętnastu pt. Weź je za rękę. Jak chronić dziecko przed zagrożeniami technologii i ideologii ${ }^{3}$, który w przystępnej formie dostarcza informacji i rekomendacji na temat współczesnego kontekstu wychowawczego ze szczególnym odniesieniem do mediów i technologii cyfrowych. W kwietniu 2020 roku Fundacja przeprowadziła badanie wpływu epidemii koronawirusa na opinie i preferencje maturzystów i opublikowała raport Koronawirus a matura - raport z badania ankietowego.

Organizacja ma na swoim koncie także działania w obszarze konsultowania i upowszechniania dobrych praktyk polityki rodzinnej w gminach. W lipcu 2019 roku we współpracy z KGHM zorganizowaliśmy warsztaty dla samorządowców w Lubinie. Warto także nadmienić, że kilkoro członków i ekspertów Fundacji zostało powołanych do Rady Rodziny przy MRPiPS, Rady Rodziny przy wojewodzie wielkopolskim, Zespołu ds. Bezpieczeństwa Dzieci i Młodzieży przy wojewodzie wielkopolskim. Ponadto jej prezes, dr hab. prof. UAM Michał A. Michalski, jest członkiem Rady Naukowej Instytutu Pracy i Spraw Socjalnych oraz kwartalnika „Niepełnosprawność” Państwowego Funduszu Rehabilitacji Osób Niepełnosprawnych. Oprócz tego Fundacja regularnie współpracuje z takimi organizacjami pozarządowymi, jak poznańska Społeczna Rada ds. Edukacji i Wychowania, Fundacja Edukacji Zdrowotnej i Psychoterapii, Polska Izba Biznesu - Wielkopolska Izba Gospodarcza oraz Instytut Kultury Prawnej Ordo Iuris.

Fundacja zaprasza do kontaktu oraz współpracy! Więcej informacji na temat Fundacji Instytut Wiedzy o Rodzinie i Społeczeństwie oraz PFR na stronach internetowych www.iworis.pl. oraz www.polskieforumrodzicow.pl.

3 Weź je za rękę. Jak chronić dziecko przed zagrożeniami technologii i ideologii?, Poznań 2020. 
III. Wymiary duchowości rodziny 
